\section{Kidney \\ Blood Pressure Research}

Kidney Blood Press Res 2017;42:33-42

DOI: $10.1159 / 000468530$

Published onlıne: March 13, 2017

Accepted: January 17, 2017

This article is licensed under the Creative Commons Attribution-NonCommercial-NoDerivatives 4.0 InternaThis article is licensed under the Creative Commons Attribution-NonCommercial-NoDerivatives 4.0 Interna-
tional License (CC BY-NC-ND) (http:/ /www.karger.com/Services/OpenAccessLicense). Usage and distribution for commercial purposes as well as any distribution of modified material requires written permission.

\title{
Magnesium Replacement Improves the Metabolic Profile in Obese and Pre-Diabetic Patients with Mild-to-Moderate Chronic Kidney Disease: A 3-Month, Randomised, Double-Blind, Placebo-Controlled Study
}

\author{
Omer Toprak ${ }^{a^{*}}$ Huseyin Kurt ${ }^{\mathrm{b}}$ Yasin Sarı ${ }^{\mathrm{b}}$ Cihat Şarkış ${ }^{\mathrm{c}}$ Halil Us ${ }^{\mathrm{b}}$ \\ Ali Kırık
}

aDepartment of Medicine, Division of Nephrology; ${ }^{b}$ Department of Medicine, Division of Internal Medicine; 'Department of Medicine, Division of Gastroenterology, Balikesir University School of Medicine, Balikesir, Turkey

\section{Key Words}

Chronic kidney disease $\bullet$ Hypomagnesemia $•$ Obesity $\bullet$ Insulin resistance $•$ Pre-diabetes

\begin{abstract}
Background/Aims: Magnesium is an essential mineral for many metabolic functions. There is very little information on the effect of magnesium supplementation on metabolic profiles of chronic kidney disease (CKD) patients. The aim of this study was to assess the influence of magnesium supplementation on metabolic profiles of pre-diabetic, obese and mild-tomoderate CKD patients with hypomagnesemia. Methods: A total of 128 hypomagnesemic, pre-diabetic and obese patients with an estimated glomerular filtration rate between 90 and $30 \mathrm{ml} / \mathrm{min} / 1.73 \mathrm{~m}^{2}$ were enrolled in a randomised, double-blind, placebo-controlled trial. Patients in the magnesium group received $365 \mathrm{mg}$ of oral magnesium $(n=57)$ once daily for 3 months, while patients in the control group received a placebo $(n=61)$, also once daily for 3 months. Hypomagnesemia is defined by a serum magnesium level $<1.8 \mathrm{mg} / \mathrm{dl}$ in males and $<1.9 \mathrm{mg} / \mathrm{dl}$ in females; obesity is defined as a body mass index $\geq 30 \mathrm{~kg} / \mathrm{m}^{2}$; and pre-diabetes is defined as fasting plasma glucose $\geq 100$ but $<126 \mathrm{mg} / \mathrm{dl}$. The primary end point of the study was the change in insulin resistance measured by the homeostastic model assessment for insulin resistance (HOMA-IR). Results: At the end of follow-up, insulin resistance (-24.5 vs. $-8.2 \%, P=0.007)$, HOMA-IR index (-31.9 vs. $-3.3 \%, P<0.001)$, hemoglobin A1c $(-6.6$ vs. $-0.16 \%$, $P<0.001)$, insulin $(-29.6$ vs. $-2.66 \%, P<0.001)$, waist circumference $(-4.8$ vs. $0.55 \%, P<0.001)$ and uric acid ( -0.8 vs. $2.2 \%, P=0.004)$ were significantly decreased in terms of mean changes; albumin (0.91 vs. $-2.91 \%, P=0.007)$ and magnesium $(0.21 \pm 0.18$ vs. $-0.04 \pm 0.05 \mathrm{mg} / \mathrm{dl}, P$ $<0.001$ ) were significantly increased in those taking magnesium compared with a placebo.




\section{Kidney \\ Blood Pressure Research}

Toprak et al.: Metabolic Profile and Magnesium Therapy in Chronic Kidney Disease

The decrease in metabolic syndrome $(-10.5$ vs. $-4.9 \%, P=0.183)$, obesity $(-15.7$ vs. $-8.2 \%, P=$ $0.131)$, pre-diabetes $(-17.5$ vs. $-9.8 \%, P=0.140)$, and systolic $(-5.0 \pm 14.8$ vs. $0.22 \pm 14.9 \mathrm{~mm}$ $\mathrm{Hg}, P=0.053)$ and diastolic $(-3.07 \pm 9.7$ vs. $0.07 \pm 9.6 \mathrm{~mm} \mathrm{Hg}, P=0.071)$ blood pressure did not achieve to a significant level after study. Conclusion: Our data support the argument that magnesium supplementation improves the metabolic status in hypomagnesemic CKD patients with pre-diabetes and obesity.

\section{Introduction}

Magnesium is an essential co-factor for biochemical reactions and plays an important role in glucose metabolism [1]. Deficiency of magnesium, which is an inexpensive and nontoxic element, results in diseases that cause incalculable suffering and costs worldwide. Hypomagnesemia has been reported in patients with type 2 diabetes mellitus (DM), preDM, metabolic syndrome, insulin resistance, hyperlipidemia, hypertension and CKD (chronic kidney disease) [2-4]. Hypomagnesemia may also be associated with cardiovascular mortality and kidney function decline in CKD patients $[4,5]$. The efficacy of magnesium supplementation in improving glycemic control among non-diabetic, pre-diabetic and diabetic individuals has been suggested by some clinical trials $[1,3,6]$.

Serum glucose levels that are higher than normal but do not fulfil the definition of DM are classified as pre-DM. Diabetes is a major cause of CKD, and pre-diabetes is accompanied by an increased prevalence of CKD as well. It is reported that $17.7 \%$ of people with pre-diabetes have had CKD [7]. Most CKD observed in patients with pre-diabetes is due to macrovascular disease, especially hypertension. A high incidence of obesity and insulin resistance are other risks for developing CKD in pre-diabetics [8]. Magnesium intake reduces the risk of progression from pre-DM to DM [6]: Pre-DM is a reversible state, and magnesium deficiency is also a modifiable risk factor for the decline in kidney function $[4,9]$. In the literature, there is no information about the effect of magnesium supplementation in improving glycemic control among hypomagnesemic pre-diabetic or diabetic patients in the early stages of CKD. We hypothesise that magnesium supplementation would improve insulin resistance in hypomagnesemic obese and pre-diabetic patients with CKD. An early optimisation of magnesium may delay or decrease the incidence of DM in pre-diabetic CKD patients and return insulin resistance to normal in study patients. In this study, we examined the effect of 3-month magnesium supplementation on metabolic profiles in hypomagnesemic obese and pre-diabetic patients in stage 2 and 3 of CKD.

\section{Materials and Methods}

\section{Study Population}

A single-centre, randomised, double-blind, placebo-controlled trial was performed on patients (aged 20 to 70 years) with mild-to-moderate CKD, hypomagnesemia, pre-DM and obesity between July 2014 and April 2015 at Balikesir University School of Medicine, Department of Nephrology. The study was approved by the Ethical Committee of the university (Approval No:2014/43). All patients gave written, informed consent. A total of 128 patients met the inclusion criteria. Patients were randomly allocated to receive either magnesium (magnesium group) or placebo (placebo group) solutions, once a day for 3 months. Individuals in the magnesium group received $100 \mathrm{ml}$ of $613.20 \mathrm{mg}$ of magnesium oxide solution, equivalent to $365 \mathrm{mg}$ of elemental magnesium (Magnorm ${ }^{\circledR}$ tb, Vitalis, Istanbul, Turkey); individuals in the placebo group received $100 \mathrm{ml}$ of placebo solution, which consisted of sodium-free carbonated water. The placebo was the same in colour and appearance to the magnesium solution. Investigator and subject blinding were maintained until data collection was complete. Computer-generated random numbers were used for assigning participants to either the magnesium group or the placebo group. Both groups were advised to consume a special diet (restricted sodium intake, protein intake of $0.8 \mathrm{~g} / \mathrm{kg}$ body weight per day, total daily caloric intake of 25 $\mathrm{kcal} / \mathrm{kg} /$ day) and perform physical activity for 30 minutes per day. 


\section{Kidney Blood Pressure Research}

Analytical Methods

Blood samples taken to measure serum glucose, insulin, HbA1c (hemoglobin A1c), creatinine, urea, uric acid, parathyroid hormone, C-reactive protein (CRP), albumin, magnesium, calcium, lipids (triglyceride, high-density lipoprotein cholesterol [HDL-C], total cholesterol, low-density lipoprotein cholesterol [LDL-C]) and hemoglobin were drawn after an 8-hour overnight fasting condition and in a standing position, and follow-up parameters were measured 3 months after the magnesium treatment or placebo. Urine samples taken to measure the urine protein to urine creatinine ratio were calculated at baseline and then again 3 months later. Anthropometric measurements like weight, height, waist circumference and body mass index (BMI) were performed with the subjects wearing light clothing and no shoes. Weight and height were measured using a fixed scale with a stadiometer (Nan DR-MOD-85, Istanbul, Turkey). BMI was calculated as the weight divided by the square of the height in metres. Waist circumference was measured to the nearest $0.1 \mathrm{~cm}$ using a flexible metric measuring tape with the subject in a standing position, and the anatomic landmarks used were at the midpoint between the costal margin and the iliac crest in the mid-axillary line. Insulin resistance was estimated by using the homeostatic model assessment for insulin resistance (HOMAIR: fasting insulin $[\mu \mathrm{U} / \mathrm{mL}] \mathrm{x}$ fasting glucose $[\mathrm{mg} / \mathrm{dL}] / 405)$ [10]. Glomerular filtration rates were estimated using the Chronic Kidney Disease Epidemiological Collaboration (CKD-EPI) equation [11]. Systolic and diastolic blood pressure were measured according to the Seventh Report of the Joint National Committee on Prevention, Detection, Evaluation, and Treatment of High Blood Pressure [12].

Assays

Blood samples were collected from the antecubital vein by venipuncture into vacutainer tubes after an 8-hour overnight fasting, then centrifuged and stored at $-80{ }^{\circ} \mathrm{C}$ until analysis. Serum magnesium was analysed by the colorimetric method with a clinical chemistry autoanalyser. HbA1c was analysed by a highperformance liquid chromatography method (Menarini/ARKRAY ADAMS A1c HA-8180V analyser). Insulin levels were determined using a commercial ELISA kit. Calcium, urea and urinary protein concentrations were measured via the colorimetric method. Serum creatinine and urinary creatinine concentrations were determined enzymatically on an autoanalyser and with the Jaffé method. Uric acid levels were determined with the uricase-peroxidase method, while glucose levels were calculated via the glucose oxidase method. Albumin and CRP were determined in serum by the nephelometric method. Parathyroid hormones were measured with an enzyme-linked immunosorbent assay. Lipid profiles were analysed by enzymatic methods and with the Beckman Coulter AU680 Analyser (Beckman Coulter, Inc., CA, USA) using commercially available kits.

\section{Clinical Definitions}

Hypomagnesemia has been defined by a serum magnesium level $<1.8 \mathrm{mg} / \mathrm{dl}$ in males and $<1.9 \mathrm{mg} / \mathrm{dl}$ in females $[13,14]$ (reference ranges of magnesium in the study laboratory were $1.8-2.6 \mathrm{mg} / \mathrm{dl}$ in males and $1.9-2.5 \mathrm{mg} / \mathrm{dl}$ in females); obesity has been defined as a BMI $\geq 30 \mathrm{~kg} / \mathrm{m}^{2}$, while insulin resistance has been defined as a HOMA-IR index $\geq 3$ [15-17]; diabetes has been defined as a fasting plasma glucose level $\geq 126$ $\mathrm{mg} / \mathrm{dL}$, which can be confirmed by repeated testing, previous diagnosis of diabetes, or the current use of antidiabetic medications; lastly, pre-DM has been defined as the presence of a fasting plasma glucose level $\geq 100$ but $<126 \mathrm{mg} / \mathrm{dl}$ [18]. The identification of metabolic syndrome (MS) conformed to the definition used by the National Cholesterol Education Program Adult Treatment Panel III guidelines [19]. Those patients who had 3 or more of the following 5 components were classified as having MS: abdominal obesity, high blood pressure, hypertriglyceridemia, low HDL-C and high fasting glucose. The MS score was defined as the number of constituents of MS. According to the National Kidney Foundation Clinical Practice Guidelines, a cut-off value of $\geq 60$ to $<89 \mathrm{ml} / \mathrm{min} / 1.73 \mathrm{~m}^{2}$ in eGFR (estimated glomerular filtration rate) with kidney damage, and $\geq 30$ to $<59 \mathrm{ml} / \mathrm{min} / 1.73 \mathrm{~m}^{2}$ in eGFR regardless of kidney damage, were used to define stage 2 and 3 of CKD, respectively [20]. Kidney damage was indicated by a protein to creatinine ratio $\geq 200 \mathrm{mg} / \mathrm{g}$. The causes of CKD in study patients included hypertension (37.5\% vs. 34.3\%), glomerulonephritis $(18.7 \%$ vs. $14.1 \%)$, polycystic kidney disease (6.25\% vs $3.1 \%)$, myeloma (3.1\% vs $1.5 \%)$, pyelonephritis ( $9.3 \%$ vs. $12.5 \%)$ or unknown $(28.1 \%$ vs $34.3 \%)$ in the magnesium group and placebo group, respectively.

Adherence to pharmacological treatment, diet and exercise were assessed every month by personal interviews, tablet counts and measurements of the remaining solution, and independent interviews with individuals in charge of preparing meals for the patients. 


\section{Kidney Blood Pressure Research}

Kidney Blood Press Res 2017;42:33-42

\begin{tabular}{|l|l|}
\hline DOI: $10.1159 / 000468530$ & C 2017 The Author(s). Published by S. Karger AG, Base
\end{tabular}

Published onlıne: March 13, 2017

www.karger.com/kb

\section{Exclusion Criteria}

Exclusion criteria included malabsorption, prior history of inflammatory bowel disease or any severe gastrointestinal disorder, diarrhoeal disease, alcohol abuse, or the concurrent use of magnesium supplements, laxatives, diuretics, corticosteroids, oral contraceptives, bile acid sequestrants, magnesiumcontaining phosphate binders, proton pump inhibitors, amphotericin B, aminoglycosides, tetracycline or chemotherapy drugs. Also, any prior history of allergy or intolerance to magnesium, inherited renal tubular defects, kidney transplants, or pregnancies were counted as exclusion criteria.

\section{Sample Size}

Sample size was estimated based on a statistical power of $80 \%$ and an alpha value of 0.05 . It was estimated that 61 patients would be required in each group to detect a mean difference in insulin resistance (study endpoint) of at least $25 \%$ between the two groups at the end of the treatment period.

\section{Statistical Analysis}

The primary study endpoint was the efficacy of magnesium supplementation in reducing insulin resistance. Secondary endpoints included changes (improvement) in pre-diabetic status, obesity, fasting glucose, blood pressure, MS rates, inflammatory markers and proteinuria. Comparisons of continuous variables between groups were performed using a Student's $t$-test for normally distributed data and the Mann-Whitney U-test for non-normally distributed data. Within-subject comparisons of continuous variables were carried out using a paired $t$-test or the Wilcoxon signed-rank test for normally and nonnormally distributed data, respectively. Categorical variables were analysed using the chi-square test or, alternatively, the Fisher's exact test. All tests were 2 -sided, and a $p$-value of $<0.05$ was considered statistically significant. Continuous data are reported as mean \pm SD. Categorical data are presented as absolute values and percentages. Analyses were performed using the IBM SPSS Statistics Version 20.0 (IBM Corp., USA).

\section{Results}

Screening was performed on 2,335 patients, 2,207 (97.2\%) of whom were excluded because they either did not fulfil the inclusion criteria or met the criteria for exclusion. A total of 128 patients were enrolled and randomly allocated to the study groups, although 7 patients from the magnesium group and 3 from the placebo group dropped out. Thus, a total of 118 patients, 57 from the magnesium group and 61 from the placebo group, successfully completed the study (Fig. 1). Magnesium was well tolerated in study patients. Only slight epigastric pain and mild diarrhoea were documented in 3 patients (5.2\%) from the magnesium group and 1 patient $(1.6 \%)$ from the placebo group $(P=0.104)$. The adverse effects did not require treatment and were resolved within 24 hours of ceasing intake of magnesium or the placebo. No significant difference in adherence to treatment (89.1\% to $95.3 \%$ ) and adherence to diet and exercise (96.5\% to $96.7 \%$ ) was found between the magnesium and placebo groups, respectively. Baseline characteristics were not statistically different between the groups in terms of anthropometric and biochemical variables (Table 1). The following baseline parameters were also non-significant between the groups: gender $(P=0.13)$, weight $(P=0.311)$, parathyroid hormones $(P=0.705)$, calcium $(P=0.120)$, hemoglobin $(P=0.523)$, CRP $(P=0.86)$, total cholesterol $(P=0.94)$, LDL-C $(P=0.613)$, MS score $(P=0.376)$, urea $(P=0.83)$ and creatinine $(P=0.205)$. Moreover, the use of calcium supplements because of CKD $(P=0.780)$ and oral antidiabetics because of insulin resistance $(P=0.650)$ were also non-significant between the groups ( 4 patients in the magnesium group and 5 in the placebo group received either vildagliptin or sitagliptin). Prescriptions for uric acid-lowering drugs, statins and RAS inhibitors were also non-significant between the groups. At the end of the follow-up, waist circumference $(P=0.036)$, systolic $(P=0.035)$ and diastolic $(P=0.039)$ blood pressure, $\operatorname{HbA1c}(P=0.001)$, fasting insulin $(P=0.035)$ and HOMAIR index $(P=0.018)$ had decreased, while magnesium levels had increased $(P<0.001)$ in the magnesium group compared with the placebo group. In addition, when the basal and final conditions in the magnesium group were compared, the following changes were significant: insulin resistance $(70.1 \%$ to $45.6 \%, P<0.001)$, HOMA-IR index $(4.67 \pm 2.77$ to $3.17 \pm 1.93, P$ $<0.001)$, insulin (17.11 \pm 10.23 to $12.03 \pm 7.31 \mathrm{mmol} / \mathrm{l}, P<0.001)$, fasting glucose $(110.77 \pm$ 


\section{Kidney Blood Pressure Research}

Fig. 1. Flow diagram of study participants from enrolment to analysis.

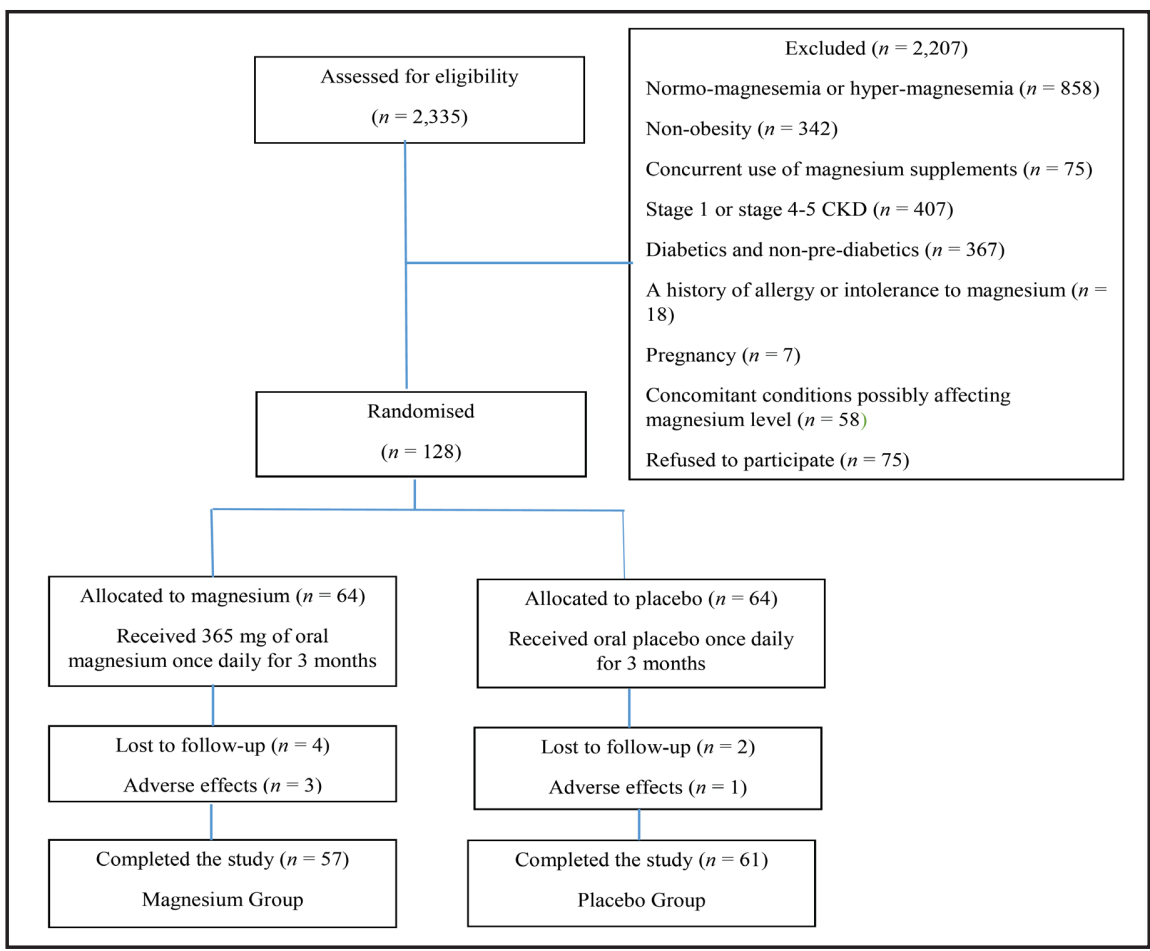

Table 1. Study variables in the magnesium and placebo groups before and after intervention Values are expressed as mean \pm SD or number (\%) of patients. Mg: magnesium; SBP: systolic blood pressure; DBP: diastolic blood pressure; HDL: high density lipoprotein; P/C: protein/creatinine; BMI: body mass index; WC: waist circumference. ${ }^{*} P<0.001,{ }^{* *} P$ $<0.02$ between the basal and final condition in the magnesium group.

\begin{tabular}{lcccccc}
\hline & \multicolumn{3}{c}{ Basal } & \multicolumn{2}{c}{ Final } \\
\cline { 2 - 7 } & $\begin{array}{c}\text { Magnesium } \\
(n=57)\end{array}$ & $\begin{array}{c}\text { Placebo } \\
(n=61)\end{array}$ & $\begin{array}{c}P \\
\text { value }\end{array}$ & $\begin{array}{c}\text { Magnesium } \\
(n=57)\end{array}$ & $\begin{array}{c}\text { Placebo } \\
(n=61)\end{array}$ & $\begin{array}{c}P \\
\text { value }\end{array}$ \\
\hline Age, years & $55.58 \pm 13.75$ & $57.09 \pm 12.91$ & 0.528 & - & - & - \\
BMI, kg/m & $33.86 \pm 2.81$ & $33.99 \pm 2.63$ & 0.794 & $32.90 \pm 3.21$ & $33.88 \pm 2.83$ & 0.376 \\
WC, cm & $104.54 \pm 11.3$ & $103.17 \pm 10.98$ & 0.493 & $99.5 \pm 11.07^{*}$ & $103.72 \pm 11.01$ & 0.036 \\
SBP, mm Hg & $130.7 \pm 14.4$ & $131.5 \pm 17.7$ & 0.78 & $125.7 \pm 14.6^{* *}$ & $131.74 \pm 6.78$ & 0.035 \\
DBP, mm Hg & $73.42 \pm 10.05$ & $74.06 \pm 12.64$ & 0.758 & $70.35 \pm 8.6^{* *}$ & $74.13 \pm 11.21$ & 0.039 \\
Glucose, mg/dl & $110.77 \pm 5.46$ & $111.32 \pm 6.55$ & 0.617 & $106.9 \pm 8.95^{*}$ & $109.8 \pm 9.57$ & 0.088 \\
HOMA-IR index & $4.67 \pm 2.77$ & $4.23 \pm 2.42$ & 0.347 & $3.17 \pm 1.93^{*}$ & $4.07 \pm 2.21$ & 0.018 \\
Insulin resistance & $40(70.1 \%)$ & $42(68.9 \%)$ & 0.805 & $26(45.6 \%)^{*}$ & $37(60.6 \%)$ & 0.089 \\
HbA1c, \% & $6.05 \pm 0.31$ & $5.95 \pm 0.35$ & 0.111 & $5.65 \pm 0.47^{*}$ & $5.94 \pm 0.50$ & 0.001 \\
Metabolic syndrome & $38(66.6 \%)$ & $41(67.2 \%)$ & 0.407 & $32(56.1 \%)$ & $38(62.3 \%)$ & 0.660 \\
Triglyceride, mg/dl & $164.1 \pm 60.94$ & $169.2 \pm 73.2$ & 0.674 & $152.3 \pm 54.2$ & $169.1 \pm 91.9$ & 0.228 \\
HDL-C, mg/dl & $46.18 \pm 11.84$ & $48.29 \pm 13.52$ & 0.358 & $47.51 \pm 12.04$ & $48.62 \pm 13.72$ & 0.633 \\
Uric acid, mg/dl & $6.16 \pm 1.82$ & $5.89 \pm 1.58$ & 0.385 & $5.66 \pm 1.32^{* *}$ & $6.03 \pm 1.64$ & 0.164 \\
eGFR, ml/min/1.73m ${ }^{2}$ & $55.28 \pm 16.15$ & $50.69 \pm 12.54$ & 0.075 & $52.60 \pm 16.15$ & $49.75 \pm 14.62$ & 0.279 \\
Urine P/C, mg/dl & $0.43 \pm 0.56$ & $0.54 \pm 0.71$ & 0.345 & $0.36 \pm 0.48^{*}$ & $0.56 \pm 0.69$ & 0.073 \\
Serum albumin, gr/dl & $4.36 \pm 0.31$ & $4.46 \pm 0.56$ & 0.275 & $4.41 \pm 0.56$ & $4.32 \pm 0.41$ & 0.236 \\
Serum magnesium, mg/dl & $1.70 \pm 0.13$ & $1.72 \pm 0.08$ & 0.531 & $1.91 \pm 0.22^{*}$ & $1.69 \pm 0.12$ & $<0.001$ \\
\hline
\end{tabular}

5.46 to $106.9 \pm 8.95 \mathrm{mg} / \mathrm{dl}, P<0.001)$, uric acid $(6.16 \pm 1.82$ to $5.66 \pm 1.32 \mathrm{mg} / \mathrm{dl}, P<0.02)$, HbA1c ( $6.05 \pm 0.31$ to $5.65 \pm 0.47 \%, P<0.001)$, waist circumference $(104.54 \pm 11.30$ to 99.54 $\pm 11.07 \mathrm{~cm}, P<0.001)$, systolic (130.7 \pm 14.4 to $125.7 \pm 14.6 \mathrm{~mm} \mathrm{Hg}, P<0.02)$ and diastolic $(73.42 \pm 10.05$ to $70.35 \pm 8.6 \mathrm{~mm} \mathrm{Hg}, P<0.02)$ blood pressure, urine protein to creatinine ratio $(0.43 \pm 0.56$ to $0.36 \pm 0.48 \mathrm{mg} / \mathrm{dl}, P<0.001)$ and magnesium levels $(1.70 \pm 0.13$ to 1.91 $\pm 0.22 \mathrm{mg} / \mathrm{dl}, P<0.001$ ). No change in any parameter in the placebo group between basal and final conditions was observed (Table 1). In spite of the decrease in systolic and diastolic blood pressure, fasting glucose levels, and urine protein to creatinine ratios in the magnesium group, changes in the compared means after treatment did not show significant differences between the two groups $(P=0.053, P=0.071, P=0.087$, and $P=0.075$, respectively) (Table 2). Despite the non-significant increase in albumin levels in the magnesium group, changes in the means after treatment did show a significant increase $(0.04 \pm 0.18$ to $-0.13 \pm 0.45$, $P=0.007)$. A summary of the significant mean changes after treatment by percentage is 


\section{Kidney Blood Pressure Research}

Toprak et al.: Metabolic Profile and Magnesium Therapy in Chronic Kidney Disease

presented in Fig. 2. Levels of triglycerides $(-11.84 \pm 35.1 \mathrm{mg} /$ dl, $P=0.214)$, LDL-C $(-3.52 \pm 20.4$ $\mathrm{mg} / \mathrm{dl}, P=0.257)$, BMI $(-0.96 \pm$ $\left.1.35 \mathrm{~kg} / \mathrm{m}^{2}, P=0.146\right)$, weight $(-2.22 \pm 3.09 \mathrm{~kg}, P=0.132)$, MS rates $(-10.5 \%, P=0.183)$, MS score $(-0.40 \pm 0.97, P=0.166)$, obesity rates $(-15.7 \%, P=0.131)$ and preDM status $(-17.5 \%, P=0.140)$ were decreased, while HDL-C increased $(+1.33 \pm 6.7 \mathrm{mg} / \mathrm{dl}, P$ $=0.39$ ) in the magnesium group after the magnesium treatment; however, this increase was not significant (Table 2). During the follow-up, there were no changes from pre-DM to DM.
Table 2. Mean changes in magnesium, metabolic and renal parameters after treatment $\Delta$ : mean change from baseline to endpoint between the beginning and end of the study.

\begin{tabular}{lccc}
\hline Parameters & Magnesium & Placebo & $P$ value \\
\hline$\Delta$ Magnesium, mg/dl & $0.21 \pm 0.18$ & $-0.04 \pm 0.05$ & $<0.001$ \\
$\Delta$ HbA1c, \% & $-0.40 \pm 0.35$ & $-0.01 \pm 0.38$ & $<0.001$ \\
$\Delta$ Fasting insulin, mmol/l & $-5.07 \pm 4.30$ & $-0.41 \pm 2.69$ & $<0.001$ \\
$\Delta$ HOMA-IR index & $-1.49 \pm 1.18$ & $-0.16 \pm 0.86$ & $<0.001$ \\
$\Delta$ Insulin resistance, $n(\%)$ & $14(-24.5 \%)$ & $5(-8.2 \%)$ & 0.007 \\
$\Delta$ Pre-diabetes, $n(\%)$ & $10(-17.5 \%)$ & $6(-9.8 \%)$ & 0.140 \\
$\Delta$ Obesity, $n(\%)$ & $9(-15.7 \%)$ & $5(-8.2 \%)$ & 0.131 \\
$\Delta$ Metabolic syndrome, $n(\%)$ & $6(-10.5 \%)$ & $3(-4.9 \%)$ & 0.183 \\
$\Delta$ Metabolic syndrome score & $-0.40 \pm 0.97$ & $-0.18 \pm 0.75$ & 0.166 \\
$\Delta$ Fasting glucose, mg/dl & $-3.84 \pm 6.4$ & $-1.52 \pm 8.2$ & 0.087 \\
$\Delta$ Triglycerides, mg/dl & $-11.84 \pm 35.1$ & $-0.22 \pm 62.5$ & 0.214 \\
$\Delta$ HDL cholesterol, mg/dl & $+1.33 \pm 6.7$ & $+0.33 \pm 5.5$ & 0.36 \\
$\Delta$ LDL cholesterol, mg/dl & $-3.52 \pm 20.4$ & $+0.07 \pm 15.0$ & 0.257 \\
$\Delta$ Waist circumference, cm & $-5.0 \pm 3.01$ & $+0.55 \pm 3.19$ & $<0.001$ \\
$\Delta$ Body mass index, kg/m ${ }^{2}$ & $-0.96 \pm 1.35$ & $-0.61 \pm 1.35$ & 0.146 \\
$\Delta$ Uric acid, mg/dl & $-0.05 \pm 1.4$ & $0.13 \pm 0.9$ & 0.004 \\
$\Delta$ Albumin, gr/dl & $0.04 \pm 0.18$ & $-0.13 \pm 0.45$ & 0.007 \\
\hline Renal Parameters & & & \\
\hline$\Delta$ eGFR, ml/min/1.73m ${ }^{2}$ & $-2.68 \pm 5.2$ & $-0.96 \pm 5.4$ & 0.075 \\
$\Delta$ Urine protein to creatinine ratio & $-0.07 \pm 0.12$ & $0.01 \pm 0.34$ & 0.075 \\
$\Delta$ Systolic blood pressure, mmHg & $-5.0 \pm 14.8$ & $+0.22 \pm 14.9$ & 0.053 \\
$\Delta$ Diastolic blood pressure, mmHg & $-3.07 \pm 9.7$ & $+0.07 \pm 9.6$ & 0.071 \\
\hline
\end{tabular}

Fig. 2. Significant mean changes by percentage in metabolic parameters after treatment in the study groups. HOMA-IR, homeostatic model assessment for insulin resistance, HbA1c, hemoglobin A1c.

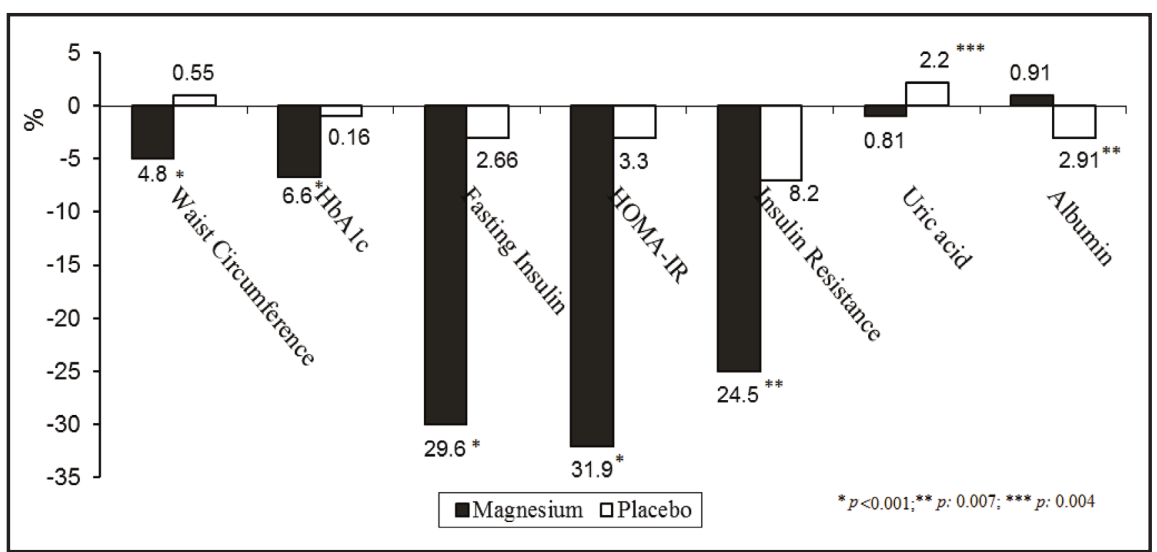

\section{Discussion}

In this study, we showed that a 3-month oral administration of magnesium oxide improved the metabolic profile - and especially insulin sensitivity - in pre-diabetic and obese patients with stage 2 and 3 CKD. Although the role of magnesium in glucose metabolism has already been demonstrated in diabetics without CKD [6,21-23], this study is valuable insofar as it confirms the beneficial effects of magnesium among CKD patients. This is the first study to demonstrate the influence of magnesium on the metabolic profile of hypomagnesemic patients in the early stages of CKD.

Associations between hypomagnesemia and an increased risk for type 2 DM, pre-DM, insulin resistance, obesity, dyslipidemia, hypertension and MS have been shown in various studies [21-29]. All of these conditions have a high incidence of hypomagnesemia as well as increased risk for cardiovascular mortality [24-26]. Our study groups were recruited from these high-risk patients. Magnesium is essential for insulin secretion, post-receptor insulin signalling, and the glycolytic pathway [1]. The efficacy of magnesium supplementation in improving glycemic control among non-diabetics [30,31], pre-diabetics [32-34] and diabetics $[23,35,36]$ has been suggested in some trials. A recent meta-analysis documented that magnesium is effective in decreasing the HOMA-IR index $(P=0.013)$ but has no effect on glucose, HbA1c or insulin. However, magnesium supplementation for $\geq 4$ months improves 


\section{Kidney Blood Pressure Research}

the HOMA-IR index $(P=0.001)$ and glucose levels $(P<0.001)$ in both diabetics and nondiabetics [3]. In agreement with this report, in our study, magnesium significantly reduced the HOMA-IR index but the glucose level was not decreased significantly. If we had increased the duration of magnesium supplementation from 3 months to 4 months, the decrease of glucose would have been significant. A trial of $\mathrm{MgCl}_{2}$ for 16 weeks in patients with type 2 diabetes demonstrated improvement in the HOMA-IR index, fasting glucose levels, and HbA1c [23]. In another trial, it was shown that daily magnesium supplementation in overweight individuals significantly decreased fasting insulin [37]. In one recent study, HOMA-IR indices and glucose levels were decreased in patients with hypomagnesaemia and pre-DM after treatment with magnesium, and $50.8 \%$ of the participants in the magnesium group and $7.0 \%$ in the placebo group had decreased glucose levels $(P<0.005)$ [32]. The results of that study are compatible with ours: HbA1c, fasting insulin and insulin resistance were all decreased in our study; however, the incidence of improved glucose status (glucose $<100 \mathrm{mg} / \mathrm{dl}$ after the study) in the magnesium group was only $17.5 \%$, which was not significant. Some negative studies about the effect of magnesium on glucose, HbA1c, insulin and HOMA-IR, and lipid profiles in diabetics also exist [36]. These mixed results may be attributable to amount or the duration of supplementation. Other studies have investigated the effect of magnesium on MS and obesity [15, 38, 39]. In most of them, magnesium has improved the metabolic profile in obese and MS patients. However, Lima et al. demonstrated that magnesium does not reduce insulin resistance or HOMA-IR in MS [39]. In our study, all patients were obese and most had MS. The incidence of MS, MS scores and obesity were not decreased significantly after magnesium supplementation. Perhaps if the dose or duration of magnesium had been increased, the results would have been significant.

Data about the effect of magnesium on waist circumference is scarce. Increased waist circumference plays a role in insulin resistance and is a component of MS. In our study, there was a significant reduction in waist circumference after magnesium treatment, which may be attributable to the significant decrease in insulin resistance. Different results about the effect of magnesium on lipids in diabetic, pre-diabetic or obese patients have been generated. Some studies have documented that magnesium supplementation increases HDL-C levels [32, 40] and decreases levels of triglycerides and LDL-C [35, 40]. In our study, we found no such benefical effect of magnesium on lipids. Although HDL-C was increased, triglycerides, LDL-C and total cholesterol were decreased after magnesium treatment; yet, these changes were not significant. Another study had the same results as ours, demonstrating that magnesium does not improve the lipid profile in patients with MS [39]. Also, Mooren et al. showed that magnesium has no effect on lipids in non-diabetic, overweight or insulin-resistant subjects [31].

Magnesium deficiency is related to a rise in pro-inflammatory cytokines and acute-phase proteins $[41,42]$. Elevated serum uric acid is an inflammatory marker and is related to insulin resistance, pre-DM and MS $[43,44]$. Albumin is also a nutritional and inflammatory marker. We found no other study that has reported on the effect of magnesium supplementation on albumin and uric acid in hypomagnesemic patients. In our study, we showed that magnesium supplementation decreased uric acid and increased mean albumin. However, the CRP level was not changed. One possible explanation for this is that the decrase in insulin resistance may have helped to decrease uric acid and increase albumin levels. In the literature, it has been shown that magnesium supplementation decreases high-sensitive CRP, tumor necrosis factor-alpha, and interleukin-6 [41, 42]. In our study, we did not measure high-sensitive CRP, which may account for the failure to detect a significant decrease in CRP. Similarly, SimentalMendía et al. did not show a beneficial effect of magnesium on CRP levels in hypomagnesemic patients [33].

Studies on CKD patients have reported that hypomagnesemia is a predictor for the progression of type 2 diabetic nephropathy to end-stage kidney disease [45] and is associated with incidental kidney disease [5, 46] and accelerated loss of kidney function in renal allografts and transplant recipients [9, 47]. Hemodialysis patients with hypomagnesemia are at high risk for cardiovascular death [24-26]. However, the impact of magnesium on kidney function and metabolic profile in CKD has been poorly investigated thus far. In a trial in hypomagnesemic patients, magnesium improved glycemia after kidney transplantation [48]. 


\section{Kidney Blood Pressure Research}

In another study, carotid intima-media thickness was decreased after magnesium treatment in patients on hemodialysis [49]. Other studies have shown that magnesium reduces blood pressure $[15,50]$. However, in our study, we did not observe a strong effect of magnesium on blood pressure. Compatible with our results, blood pressure was not significantly decreased in insulin-resistant subjects after magnesium supplementation [31]. Likewise, we found no significant change in renal parameters after magnesium treatment. Although not statistically significant, magnesium supplementation decreased blood pressure levels, urine protein levels, and eGFR. These results may imply that magnesium supplementation alleviates glomerular hyperfiltration via the relationship between magnesium and the renin-angiotensin system [51].

The current study has some limitations. First, the results should be generalised with caution, since the study was conducted at a single centre. Second, the results should also be interpreted with caution because the serum magnesium measured in this study is not a reliable parameter for intracellular magnesium. Most magnesium is found in bones and only ionised, free magnesium is biologically active. Third, we have no information about the causes of hypomagnesemia. Possible causes of hypomagnesmia in our study patients included decreased dietary intake or renal loss; however, we did not measure the renal loss of magnesium.

\section{Conclusion}

How can the findings of the present study be adapted to clinical practice? The diagnosis of obesity, pre-DM or CKD is not difficult, and magnesium measurement is an easily available and inexpensive marker. Therefore, checking magnesium levels in metabolically disturbed pre-diabetic and obese patients with stage 2-3 CKD is recommended. If hypomagnesemia is detected, magnesium supplementation can be a useful guide for improving the metabolic status in these patients. In conclusion, oral magnesium administration seems to improve metabolic status in pre-diabetic, obese and stage 2-3 CKD patients with hypomagnesemia.

\section{Disclosure Statement}

The authors of this manuscript state that they do not have any conflict of interests and nothing to disclose.

\section{References}

1 Gröber U, Schmidt J, Kisters K: Magnesium in Prevention and Therapy. Nutrients 2015;7:8199-8226.

2 Geiger H, Wanner C: Magnesium in disease. Clin Kidney J 2012;5:i25-i38.

-3 Simental-Mendía LE, Sahebkar A, Rodríguez-Morán M, Guerrero-Romero F: A systematic review and meta-analysis of randomized controlled trials on the effects of magnesium supplementation on insulin sensitivity and glucose control. Pharmacol Res 2016;111:272-282.

4 Floege J: Magnesium in CKD: more than a calcification inhibitor? J Nephrol 2015;28:269-277.

-5 Tin A, Grams ME, Maruthur NM, Astor BC, Couper D, Mosley TH, Selvin E, Coresh J, Kao WH: Results from the Atherosclerosis Risk in Communities study suggest that low serum magnesium is associated with incident kidney disease. Kidney Int 2015;87:820-827.

6 Hruby A, Meigs JB, O'Donnell CJ, Jacques PF, McKeown NM: Higher magnesium intake reduces risk of impaired glucose and insulin metabolism and progression from prediabetes to diabetes in middle-aged americans. Diabetes Care 2014;37:419-427.

7 Plantinga LC, Crews DC, Coresh J, Miller ER $3^{\text {rd }}$, Saran R, Yee J, Hedgeman E, Pavkov M, Eberhardt MS, Williams DE, Powe NR; CDC CKD Surveillance Team: Prevalence of chronic kidney disease in US adults with undiagnosed diabetes or prediabetes. Clin J Am Soc Nephrol 2010;5:673-682.

$>8$ Grundy SM: Pre-diabetes, metabolic syndrome, and cardiovascular risk. J Am Coll Cardiol 2012;59:635643. 


\section{Kidney \\ Blood Pressure Research}

\begin{tabular}{l|l}
\hline Kidney Blood Press Res 2017;42:33-42 \\
\hline $\begin{array}{l}\text { DOI: 10.1159/000468530 } \\
\text { Published onlIne: March 13, } 2017\end{array}$ & $\begin{array}{l}\text { (c) } 2017 \text { The Author(s). Published by S. Karger AG, Basel } \\
\text { www.karger.com/kbr }\end{array}$
\end{tabular}

Toprak et al.: Metabolic Profile and Magnesium Therapy in Chronic Kidney Disease

-9 Van Laecke S, Nagler EV, Verbeke F, Van Biesen W, Vanholder R: Hypomagnesemia and the risk of death and GFR decline in chronic kidney disease. Am J Med 2013;126: 825-831.

10 Matthews DR, Hosker JP, Rudenski AS, Naylor BA, Treacher DF, Turner RC: Homeostasis model assessment: insulin resistance and beta-cell function from fasting plasma glucose and insulin concentrations in man. Diabetologia 1985;28:412-419.

11 Levey AS, Stevens LA, Schmid CH, Zhang YL, Castro AF 3rd, Feldman HI, Kusek JW, Eggers P, Van Lente F, Greene T, Coresh J; CKD-EPI (Chronic Kidney Disease Epidemiology Collaboration): A new equation to estimate glomerular filtration rate. Ann Intern Med 2009;150:604-612.

-12 Chobanian AV, Bakris GL, Black HR, Cushman WC, Green LA, Izzo JL Jr, Jones DW, Materson BJ, Oparil S, Wright JT Jr, Roccella EJ; Joint National Committee on Prevention, Detection, Evaluation, and Treatment of High Blood Pressure; National Heart, Lung, and Blood Institute; National High Blood Pressure Education Program Coordinating Committee: Seventh report of the Joint National Committee on Prevention, Detection, Evaluation, and Treatment of High Blood Pressure. Hypertension. 2003;42:1206-1252.

13 Thomas L: Clinical laboratory diagnostics: Use and assessment of clinical laboratory results. TH-Books Verlagsgesellschaft. Frankfurt, 1998, pp. 231-241.

14 Ali AA, Bakr RM, Yousif M, Foad RE: Assessment of serum magnesium level in patients with bronchial asthma. Egypt J Chest Dis Tuberc 2015;64:535-539.

15 Rodríguez-Moran M, Guerrero-Romero F: Oral magnesium supplementation improves the metabolic profile of metabolically obese, normal-weight individuals: a randomized double-blind placebo-controlled trial. Arch Med Res 2014;45:388-393.

16 Anuurad E, Tracy RP, Pearson TA, Kim K, Berglund L: Synergistic role of inflammation and insulin resistance as coronary artery disease risk factors in African Americans and Caucasians. Atherosclerosis 2009;205:290-295.

-17 Inzucchi SE, Viscoli CM, Young LH, Furie KL, Gorman M, Lovejoy AM, Dagogo-Jack S, Ismail-Beigi F, Korytkowski MT, Pratley RE, Schwartz GG, Kernan WN; IRIS Trial Investigators: Pioglitazone prevents diabetes in patients with insulin resistance and cerebrovascular disease. Diabetes Care 2016;39:16841692.

18 American Diabetes Association: Diagnosis and classification of diabetes mellitus. Diabetes Care 2014;37:S81-S90.

19 Executive Summary of the Third Report of the National Cholesterol Education Program (NCEP) Expert Panel on Detection, Evaluation, and Treatment of High Blood Cholesterol in Adults (Adult Treatment Panel III): JAMA 2001;285:2486-2497.

-20 National Kidney Foundation: K/DOQI clinical practice guidelines for chronic kidney disease: evaluation, classification, and stratification. Am J Kidney Dis 2002;39:S1-266.

21 Bertinato J, Wu Xiao C, Ratnayake WM, Fernandez L, Lavergne C, Wood C, Swist E: Lower serum magnesium concentration is associated with diabetes, insulin resistance, and obesity in South Asian and white Canadian women but not men. Food Nutr Res 2015;5;59:25974.

22 Simmons D, Joshi S, Shaw J: Hypomagnesaemia is associated with diabetes: Not pre-diabetes, obesity or the metabolic syndrome. Diabetes Res Clin Pract 2010;87:261-266.

-23 Rodriguez-Moran M, Guerrero-Romero F: Oral magnesium supplementation improves insulin sensitivity and metabolic control in type 2 diabetic subjects: a randomized double-blind controlled trial. Diabetes Care 2003;26:1147-1152.

24 Lacson E Jr, Wang W, Ma L, Passlick-Deetjen J: Serum Magnesium and Mortality in Hemodialysis Patients in the United States: A Cohort Study. Am J Kidney Dis 2015;66:1056-1066.

25 Li L, Streja E, Rhee CM, Mehrotra R, Soohoo M, Brunelli SM, Kovesdy CP, Kalantar-Zadeh K: Hypomagnesemia and mortality in incident hemodialysis patients. Am J Kidney Dis 2015;66:1047-1055.

-26 Sakaguchi Y, Fujii N, Shoji T, Hayashi T, Rakugi H, Isaka Y: Hypomagnesemia is a significant predictor of cardiovascular and non-cardiovascular mortality in patients undergoing hemodialysis. Kidney Int 2014;85:174-181.

-27 Guerrero-Romero F, Rascon-Pacheco RA, Rodriguez-Moran M, de la Pena JE, Wacher N: Hypomagnesaemia and risk for metabolic glucose disorders: a 10-year follow-up study. Eur J Clin Invest 2008;38:389-396.

-28 Guerrero-Romero F, Flores-García A, Saldaña-Guerrero S, Simental-Mendía LE, Rodríguez-Morán M: Obesity and hypomagnesemia. Eur J Intern Med 2016;34:29-33.

29 Šafránek R, Moučka P, Vávrová J, Palička V, Pavlíková L, Sulková SD: Changes of serum calcium, magnesium and parathyroid hormone induced by hemodialysis with citrate-enriched dialysis solution. Kidney Blood Press Res 2015;40:13-21.

-30 Guerrero-Romero F, Tamez-Perez HE, González-González G, Salinas-Martínez AM, Montes-Villarreal J, Treviño-Ortiz JH, Rodríguez-Morán M: Oral magnesium supplementation improves insülin sensitivity in non-diabetic subjects with insulin resistance. A double-blind placebo-controlled randomized trial. Diabetes 


\section{Kidney \\ Blood Pressure Research}

Toprak et al.: Metabolic Profile and Magnesium Therapy in Chronic Kidney Disease

Metab 2004;30:253-258.

-31 Mooren FC, Krüger K, Völker K, Golf SW, Wadepuhl M, Kraus A: Oral magnesium supplementation reduces insulin resistance in non-diabetic subjects - a double-blind, placebo-controlled, randomized trial. Diabetes Obes Metab 2011;13:281-284.

-32 Guerrero-Romero F, Simental-Mendía LE, Hernández-Ronquillo G, Rodriguez-Morán M: Oral magnesium supplementation improves glycaemic status in subjects with prediabetes and hypomagnesaemia: a doubleblind placebo-controlled randomized trial. Diabetes Metab 2015;41:202-207.

-33 Simental-Mendia LE, Rodriguez-Moran M, Guerrero-Romero F: Oral magnesium supplementation decreases C-reactive protein levels in subjects with prediabetes and hypomagnesemia: a clinical randomized double-blind placebo-controlled trial. Arch Med Res 2014;45:325-330.

-34 Simental-Mendía LE, Rodríguez-Morán M, Reyes-Romero MA, Guerrero-Romero F: No positive effect of oral magnesium supplementation in the decreases of inflammation in subjects with prediabetes: a pilot study. Magnes Res 2012;25:140-146.

-35 Solati M, Ouspid E, Hosseini S, Soltani N, Keshavarz M, Dehghani M: Oral magnesium supplementation in type II diabetic patients. Med J Islam Repub Iran 2014;28:67. eCollection 2014.

-36 Navarrete-Cortes A, Ble-Castillo JL, Guerrero-Romero F, Cordova-Uscanga R, Juárez-Rojop IE, AguilarMariscal H, Tovilla-Zarate CA, Lopez-Guevara Mdel R: No effect of magnesium supplementation on metabolic control and insulin sensitivity in type 2 diabetic patients with normomagnesemia. Magnes Res 2014;27:48-56.

37 Chacko SA, Sul J, Song Y, Li X, LeBlanc J, You Y, Butch A, Liu S: Magnesium supplementation, metabolic and inflammatory markers, and global genomic and proteomic profiling: a randomized, double-blind, controlled, crossover trial in overweight individuals. Am J Clin Nutr 2011;93:463-473.

-38 Guerrero-Romero F, Rodriguez-Moran M: Low serum magnesium levels and metabolic syndrome. Acta Diabetol 2002;39:209-213.

-39 Lima de Souza E Silva Mde L, Cruz T, Rodrigues LE, Ladeia AM, Bomfim O, Olivieri L, Melo J, Correia R, Porto M, Cedro A: Magnesium replacement does not improve insulin resistance in patients with metabolic syndrome: a 12-week randomized double-blind study. J Clin Med Res 2014;6:456-462.

-40 Hadjistavri LS, Sarafidis PA, Georgianos PI, Tziolas IM, Aroditis CP, Hitoglou-Makedou A, Zebekakis PE, Pikilidou MI, Lasaridis AN: Beneficial effects of oral magnesium supplementation on insulin sensitivity and serum lipid profile. Med Sci Monit 2010;16:CR307-312.

-41 Kim DJ, Xun P, Liu K, Loria C, Yokota K, Jacobs DR Jr, He K: Magnesium intake in relation to systemic inflammation, insulin resistance, and the incidence of diabetes. Diabetes Care 2010;33:2604-2610.

42 Chacko SA, Song Y, Nathan L, Tinker L, de Boer IH, Tylavsky F, Wallace R, Liu S: Relations of dietary magnesium intake to biomarkers of inflammation and endothelial dysfunction in an ethnically diverse cohort of postmenopausal women. Diabetes Care 2010;33:304-310.

43 Li C, Hsieh MC, Chang SJ: Metabolic syndrome, diabetes, and hyperuricemia. Curr Opin Rheumatol 2013;25:210-216.

44 Liu ZM, Ho SC: The association of serum C-reactive protein, uric acid and magnesium with insulin resistance in Chinese postmenopausal women with prediabetes or early untreated diabetes. Maturitas 2011;70:176-181.

45 Sakaguchi Y, Shoji T, Hayashi T, Suzuki A, Shimizu M, Mitsumoto K, Kawabata H, Niihata K, Okada N, Isaka Y, Rakugi H, Tsubakihara Y: Hypomagnesemia in type 2 diabetic nephropathy: a novel predictor of end-stage renal disease. Diabetes Care 2012;35:1591-1597.

46 Pham PC, Pham PM, Pham PA, Pham SV, Pham HV, Miller JM, Yanagawa N, Pham PT: Lower serum magnesium levels are associated with more rapid decline of renal function in patients with diabetes mellitus type 2. Clin Nephrol 2005;63:429-436.

47 Holzmacher R, Kendziorski C, Michael Hofman R, Jaffery J, Becker B, Djamali A: Low serum magnesium is associated with decreased graft survival in patients with chronic cyclosporin nephrotoxicity. Nephrol Dial Transplant 2005;20:1456-1462.

48 Van Laecke S, Nagler EV, Taes Y, Van Biesen W, Peeters P, Vanholder R: The effect of magnesium supplements on early post-transplantation glucose metabolism: a randomized controlled trial. Transpl Int 2014;27:895-902.

49 Mortazavi M, Moeinzadeh F, Saadatnia M, Shahidi S, McGee JC, Minagar A: Effect of magnesium supplementation on carotid intima-media thickness and flow-mediated dilatation among hemodialysis patients: a double-blind, randomized, placebo-controlled trial. Eur Neurol 2013;69:309-316.

-50 Kass L, Weekes J, Carpenter L: Effect of magnesium supplementation on blood pressure: a meta-analysis. Eur J Clin Nutr 2012;66:411-418.

51 Touyz RM, Yao G: Inhibitors of $\mathrm{Na}+\mathrm{Mg} 2+$ exchange activity attenuate the development of hypertension in angiotensin II-induced hypertensive rats. J Hypertens 2003;21:337-344. 